\title{
Evaporation of layers of salt solutions
}

\author{
S. Y. Misyura ${ }^{1, *}$, and $V$. S. Morozov ${ }^{1}$ \\ ${ }^{1}$ Kutateladze Institute of Thermophysics, 630090 Novosibirsk, Russia
}

\begin{abstract}
Nonisothermal evaporation of layers of water and aqueous salts solutions of $\mathrm{H}_{2} \mathrm{O} / \mathrm{LiBr}, \mathrm{H}_{2} \mathrm{O} / \mathrm{CaCl}_{2}$ and $\mathrm{H}_{2} \mathrm{O} / \mathrm{LiCl}$ was studied experimentally. The liquid layer was placed on a horizontal heated wall. The initial concentration of salt $C_{0}$ was $10 \%$. The wall temperature $T_{w}=75^{\circ} \mathrm{C}$ and ambient air pressure was 1 bar. It was shown that the heat flux $q$ increases for water for the final evaporation stage and falls for salt solutions due to the increase in salt concentration $C$ and due to a significant drop in the equilibrium partial pressure of water vapor.
\end{abstract}

\section{Introduction}

The evaporation was investigated in a considerable number of works [1-6]. The droplet and liquid evaporation is widely used in modern technologies $[1,3,6]$. Gas-droplet flow is used in technical apparatuses [6]. When burning methane hydrate vapor-gas-droplets flows are formed and a combustion temperature is significantly lowered [7]. The behavior of a layer evaporation depends on wall properties and wettability [3]. The evaporation rate depends on free convection in the solution and a degree of turbulence of a gas flow $[8,9]$. It is important to investigate the evaporation process of aqueous salt solutions for a wide range of technical tasks. The behavior of salt solution layer differs from the behavior of onecomponent liquid [10-14]. The nucleate boiling in a salt solution can be divided into several characteristic modes $[9,10]$. Heat and mass transfer in aqueous salt solutions was investigated in [15]. Crystallization on liquid surface during evaporation of a salt solution was considered in [16]. The crystallization of a salt solution depends on the heat and mass transfer [16-18]. Aqueous salt solutions can be divided into two types depending on the behavior of the evaporation rate [19]. Measurements of the velocity field in gas-droplet flow using the optical method PIV were presented in [20].

\section{Experimental data}

Fig. 1 shows the main elements of the experimental setup. The experiments were carried out at ambient air temperature $20-21^{\circ} \mathrm{C}$, relative air humidity of $30-35 \%$, and ambient air pressure 1 bar. The aqueous salt solution layers of $\mathrm{LiBr}, \mathrm{CaCl}_{2}, \mathrm{LiCl}$ and water were placed on the horizontal heated wall. The values of initial mass concentrations $C_{0}$ of a solution were determined by the densimeters. The interfacial temperature of liquid $T_{s}$ was determined with the help of thermal imager (NEC R500). Thermocouples for wall

\footnotetext{
* Corresponding author: misura@itp.nsc.ru
} 
temperature measurement $T_{w}$ were located near the wall surface $\left(T_{w}=\right.$ const $\left.=75^{\circ} \mathrm{C}\right)$. A change in the solution mass was recorded by means of the balance (5). The initial thickness of the layer in all experiments was 3-3.1 mm.

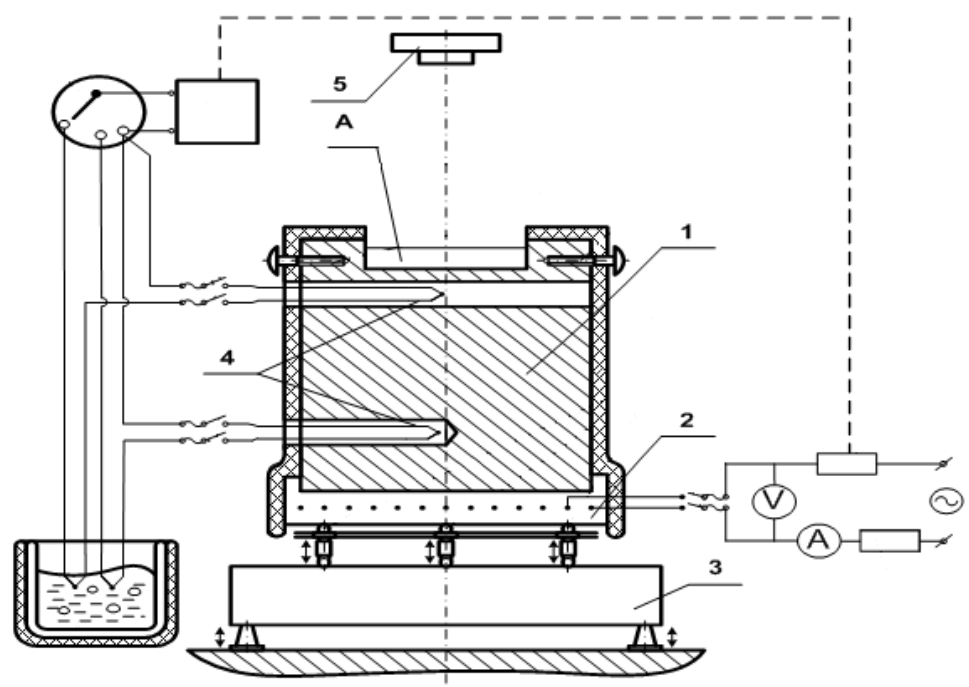

Fig. 1. Experimental setup: 1 - titanium cylinder, 2 - heater, 3 - balance, 4 - thermocouples, 5 - film and video facilities, IR imager.

The evaporation rate of the layer $j$ was determined as $j=\Delta m / \Delta t$ ( $m$ is the liquid mass and $t$ is the time). The maximum error of $j$ was $11-13 \%$ and the heat flux $q$ was $13-16 \%$. Changes in the heat flux $q$ over time are presented in Fig. 2.

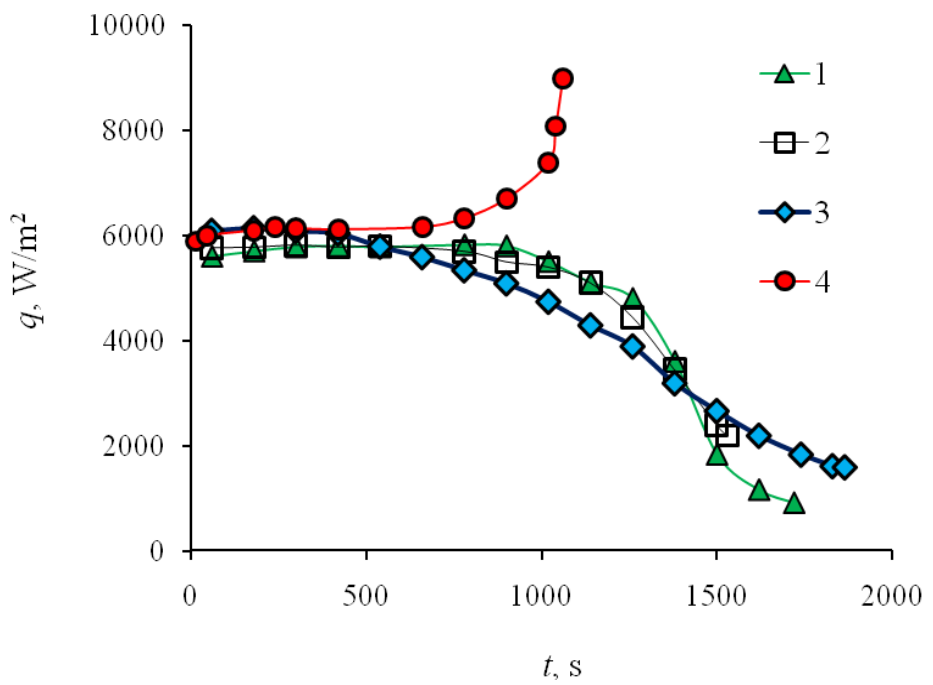

Fig. 2. Changes in the heat flux $q$ over time: $1-\mathrm{H}_{2} \mathrm{O} / \mathrm{LiBr} ; 2-\mathrm{H}_{2} \mathrm{O} / \mathrm{CaCl}_{2} ; 3-\mathrm{H}_{2} \mathrm{O} / \mathrm{LiCl} ; 4$ - water $\left(T_{w}=75^{\circ} \mathrm{C} ; C_{0}=10 \%\right.$; the initial layer thickness is $\left.3 \mathrm{~mm}\right)$.

At the initial stage, the heat flux $q$ is approximately constant for both water and salt solutions. After 500 seconds, the heat flux increases for water and falls for salt solutions due to the increase in salt concentration. The lowest heat flux corresponds to the $\mathrm{LiBr}$ salt 
concentration $C=65 \%$ near the crystallization point. In accordance with the equilibrium curves, an increase in the concentration of salt in the salt solution leads to a drop in the equilibrium partial pressure of water vapor $\left(p_{s}\right.$ for the water layer was 0.3-0.35 bar and for the aqueous solution of $\mathrm{LiBr}$ was $0.15-0.17$ bar at $t=1000-1100 \mathrm{~s}$ ).

\section{Conclusions}

Experimental studies of liquid layers of water and aqueous salt solutions of $\mathrm{LiBr}, \mathrm{LiCl}$ and $\mathrm{CaCl}_{2}$ have been carried out.

Experimental data have shown that the behavior of aqueous solutions and water is qualitatively and quantitatively different. For the salts solutions the heat flux $q$ decreases many times with increasing salt concentration, and for the water layer, the heat flux $q$ significantly increases for the final stage of evaporation.

The study of the evaporation of salt solutions layers was funded by FASO Russia.

\section{References}

1. G.V. Kuznetsov, Int. J. Heat Mass Transfer 126, 161 (2018)

2. S.Y. Misyura, Exp. Therm. Fluid Sci. 84, 190 (2017)

3. G.V. Kuznetsov, J. Eng. Thermophys. 89, 317 (2016)

4. S.Y. Misyura, Chem. Eng. Research Design 129, 306 (2018)

5. G.V. Kuznetsov, Int. J. Heat Mass Transfer 96, 20 (2016)

6. P.A. Strizhak, J. Hazardous Materials 338, 148 (2017)

7. S.Y. Misyura, Sci. Rep. 6, 30324 (2016)

8. V.P. Lebedev, Fluid dynamics 28, 624 (1993)

9. S.Y. Misyura, Sci. Rep. 7, 14759 (2017)

10. S.Y. Misyura, Int. J. Therm. Sci. 124, 76 (2018)

11. S.Y. Misyura, Int. J. Heat Mass Transfer 116, 667 (2018)

12. V.E. Nakoryakov, J. Eng. Thermophys. 20, 338 (2011)

13. S.Y. Misyura, Chem. Eng. Research Design 126, 153 (2017)

14. V.E. Nakoryakov, J. Eng. Thermophys. 25, 24 (2016)

15. V.E. Nakoryakov, Int. J. Heat Mass Transfer, 55, 6514 (2012)

16. S.Y. Misyura, Cryst Growth Des. 18, 1327 (2018)

17. A.A. Chernov, Int. J. Heat Mass Transfer 108, 1320 (2017)

18. S.Y. Misyura, Appl. Therm. Eng. 139, 203 (2018)

19. S.Y. Misyura, Int. J. Heat Mass Transfer 125, 610 (2018)

20. G.V. Kuznetsov, Appl. Therm. Eng. 131, 340 (2018) 